\title{
Processos de aprendizagem de empresas inovadoras em aglomerações produtivas: uma análise exploratória dos dados da Pintec para Santa Catarina
}

\begin{abstract}
Palauras-chave
processos de aprendizagem, sistemas locais de inovação, indústria de Santa Catarina.
\end{abstract}

\section{Classificação JEL 018, R11, R12.}

\section{Key words}

learning process, local innovation systems,

Santa Catarina industry.

JEL Classification 018 , R11, R12.

\section{Resumo}

$\mathrm{Na}$ literatura neo-schumpeteriana atual que ressalta o processo de inovação como um fenômeno sistêmico destaque-se uma linha de pesquisa que enfatiza a proximidade geográfica como indutora de processos de aprendizagem virtuosos, capazes de impulsionar a competitividade da firmas, em particular, de suas estratégias tecnológicas. O ambiente local é "aproveitado" pela firma individual conforme suas competências acumuladas e suas estratégias atuais de aprendizado. Nesse artigo, utilizamos uma tabulação especial regionalizada dos dados da Pesquisa brasileira de Inovação Tecnológica (PINTEC, II) para inferir sobre os processos locais de aprendizagem de firmas inovadoras inseridas em 9 (nove) aglomerações produtivas do estado de Santa Catarina. Os resultados apontam a localização como um componente central aos processos de aprendizagem mais virtuosos.
Pablo Felipe Bittencourt Doutorando em Economia pela UFF

Renato Ramos Campos Professor do Departamento de Economia da UFSC

\begin{abstract}
In neo-Schumpeterian current literature, which emphasizes the process of innovation as a systemic phenomenon, there is a prominent line of research that highlights geographical proximity as a stimulus to learning processes that can boost the competitiveness of firms, particularly, their technological strategies. The local environment is "exploited" by the individual firm according to its accumulated skills and their current learning strategies. In this article, using a special regionalized tabulation data from the Brazilian Innovation survey (PINTEC, II), we make inferences regarding local processes of learning of innovative firms included in 9 (nine) industrial agglomerations in the state of Santa Catarina. The results show the location as a central component to the better learning processes.
\end{abstract}




\section{1_Introdução}

O desempenho inovativo da firma depende tanto de seu esforço interno quanto da forma com que ela interage e aprende com outras firmas e instituições. Essa é a idéia básica dos chamados "sistemas de inovação", conceito que entende a geração de inovação como fruto de processos ocorridos dentro da firma, mas que é sustentado por relações que vão além da empresa vista individualmente, revelando um fenômeno sistêmico caracterizado por diferentes tipos de laço cooperativo (Cassiolato e Lastres, 2005).

Utilizando uma tabulação especial dos dados da Pesquisa Brasileira de Inovação Tecnológica (Pintec, II) - IBGE/Pintec/2005 para Santa Catarina por setor e por microrregiões -, o artigo objetiva elaborar uma análise exploratória sobre as características das estratégias de aprendizagem das firmas inovadoras inseridas em aglomerações industriais. Para tanto, são analisadas a capacitação interna das firmas, sua interação com agentes externos e o uso das fontes de informação para a inovação.

$\mathrm{O}$ artigo está organizado em quatro seções além desta introdução. Na primeira, discutem-se brevemente características locais dos processos de aprendizagem com destaque para a noção de sistemas locais de inovação. A seção dois trata da metodolo- gia do trabalho, apresenta os critérios para a seleção das aglomerações industriais e os indicadores elaborados valendo-se dos dados da Pintec. A terceira seção analisa os gastos em P\&D, o uso de fontes de informação e as relações de cooperação das empresas inovadoras inseridas em nove aglomerações produtivas selecionadas. A quarta seção, por meio da análise estatística multivariada de cluster, discute as semelhanças e as distinções nos processos de aprendizagem entre as firmas inovadoras inseridas em aglomerações. A seção quinta apresenta as conclusões.

\section{2_Processos de aprendizagem e a dimensão local}

$\mathrm{O}$ atual paradigma tecno-econômico com base nas tecnologias de informação e comunicação consolidou nos processos competitivos a centralidade do conhecimento e, portanto, da importância para as firmas das competências para aprender como um processo de constante criação e recriação de conhecimentos (learn-to-learn). Assim a habilidade de aprender passou a ser considerada crucial para o sucesso econômico dos indivíduos, empresas, regiões e economias nacionais, sendo que o "aprender" consiste em construir competências e formar habilidades novas, e não somente ter o acesso à informação. 
$\because \cdots \cdots \cdots$ 1 O conhecimento tácito é aquele que não é facilmente transferível, não pode ser facilmente difundido ou comercializado e seu fluxo é restrito ao ambiente social específico. São exemplos: competências, especializações, crenças e técnicas, além de modos implícitos e compartilhados de interpretação, os quais fazem a comunicação inteligente possível. A única forma possível de transferir o conhecimento tácito está ligada a formas de interação que se assemelham às relações de aprendiz e mestre, através de interações face a face (Foray e Lundvall, 1999).
Grande parte dos conhecimentos incorporados em indivíduos e firmas, gerados em processos de aprendizagem, apresenta um componente tácito, ${ }^{1}$ e sua transmissão implica alguma forma de relação face a face. Logo, a transmissão de conhecimentos ocorre por intermédio de processos de aprendizado determinados socialmente e que evoluem num contexto de códigos comuns de comunicação e coordenação de procedimentos de busca.

Para Lundvall (1988), as relações comerciais também geram aprendizado entre os agentes envolvidos. Para ele, os mercados reais se aproximam mais de "mercados organizados" do que dos "mercados puros" da teoria neoclássica. Nos mercados organizados, as transformações na base de conhecimento dos agentes envolvidos na interação entre produtores e usuários, por exemplo, devem ser entendidas como parte de um processo de aprendizado, no qual o produtor amplia sua capacitação inovadora, e o usuário, sua competência.

Disso deriva-se a noção do estímulo a relações face a face que emerge da proximidade locacional dos agentes, compreensão que vem sendo amplamente discutida sob o foco dos efeitos de "transbordamento" (spill-overs) do componente tácito do conhecimento.

A abordagem dos Sistemas Nacionais de Inovação (SNIs) é útil na compre- ensão desses processos uma vez que destaca o arranjo institucional de determinado espaço geográfico (nacional), associado aos esforços para tornar o progresso técnico endogenamente determinado a esse território mediante estímulos a processos interativos. Um Sistema Nacional de Inovação viabilizaria o fluxo de informações necessário a processos de inovação tecnológica, combinando, em sentido amplo, arranjos institucionais que abrangem firmas e seus laboratórios de $\mathrm{P} \& \mathrm{D}$, universidades e instituições de pesquisa, instituições educacionais, financeiras, instituições jurídicas de regulação e relações internacionais (Freeman, 1987; Lundvall, 1992).

Com base na noção de Sistema Nacional de Inovação, outras delimitações são usadas para análises empíricas, como sistemas setoriais de inovação e sistemas locais de inovação. No primeiro caso, o sistema é definido pela natureza da produção e da tecnologia, ou seja, "firmas envolvidas na atividade de desenvolvimento e producão de produtos setoriais e na geração e utilizaçãa de tecnologias setoriais" (Breschi e Malerba, 1997). No segundo caso, os limites podem ser uma região, como parte de um território nacional, ou, de forma mais restrita, um espaço geográfico no qual se concentra uma atividade produtiva. Sob essa perspectiva, a RedeSist, baseando-se em estudos empíricos no Brasil, con- 
siderando as dimensões setorial, institucional e espacial, caracterizou os "sistemas produtivos e inovativos locais" como "aglomerações territoriais de agentes econômicos, políticos e sociais - com foco em um conjunto específico de atividades econômicas - que apresentam vínculos". A consistência de tais vínculos caracterizaria certo nível de coordenação no local, estimulando a cooperação e a aprendizagem (Cassiolato e Lastres, 2003).

Um dos componentes dos sistemas locais é a concentração produtiva num determinado espaço geográfico. Essa concentração, considerando a presença no local de uma especialização produtiva, poderá, se houver coordenação e infra-estrutura de conhecimento, caracterizar um sistema local de inovação. Tal sistema poderia ser um sub sistema do nacional, ante a diversidade espacial em países com grande extensão territorial.

Neste trabalho, o termo "aglomeração produtiva" procura caracterizar essa especialização produtiva local, restringindose, portanto, às bases produtivas de um sistema local de inovação, ${ }^{2}$ uma vez que a seleção dessas aglomerações foi realizada com base nas informações da Relação Anual das Informações Sociais (Rais) do Ministério do Trabalho e Emprego (MTE) (BRASIL, 2003), que se referem ao número de firmas e de postos formais de trabalho. Com base nessa seleção, este trabalho estudou as características dos processos de aprendizagem das firmas inovadoras localizadas nessas "aglomerações produtivas".

Nesse enfoque, utilizam-se indicadores capazes de mensurar características das estratégias de capacitação e aprendizagem das firmas inseridas em aglomerações produtivas, por meio de indicadores de dispêndios em atividades de inovação, do uso de fontes de informação e das formas de cooperação para inovação, conforme apresentado na seção seguinte.

\section{3_Metodologia}

\section{1_Procedimento para a seleção de aglomerações}

O primeiro passo foi definir quais os setores $^{3}$ e regiões seriam considerados na análise. Com o uso da base de dados da Rais (BRASIL, 2003), foram adotados os seguintes procedimentos e critérios: (i) o cálculo do coeficiente locacional do emprego com valor maior do que " 1 ", conforme a expressão:

$$
Q L=\frac{\frac{E M P \text { setor } i}{\text { EMP microrregiao } j}}{\frac{\text { Total do EMP estado setor } i}{\text { Total do EMP no Estado }}}
$$

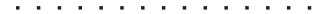

2 Algumas investigações recentes identificaram a presença de agentes locais de coordenação típicos de APL em algumas dessas estruturas. Para o caso do APL eletro-metal-mecânico de Joinville, ver Batschauer (2004); para o APL têxtil confecções de Blumenau, ver Campos, Cário e Nicolau (2000); para o APL madeireiro da região de Joaçaba, ver Enderle, Cário e Nicolau (2005); para o APL moveleiro de São Bento do Sul, ver Denk (2002); e para o APL moveleiro do Oeste do Estado, ver Geremia (2004).

3 As opções dispostas na base de dados da Relação Anual de Informações Sociais do Ministério do Trabalho e Emprego (Rais/TEM) (BRASIL, 2003) permitiram a seleção dos setores ao nível de "divisão" da Classificação Nacional da Atividade Econômica (CNAE). 
$\ldots \ldots \ldots$

4 Este foi resultado da

observação empírica e

definido com o objetivo de

obter um número de

aglomerações que expressasse

a diversidade setorial da

estrutura industrial

catarinense.

5 É importante enfatizar que

a Pintec/IBGE considera

apenas firmas com mais de dez empregados, enquanto os dados considerados até aqui observaram todas as empresas com um ou mais empregados. Entretanto, tabulando os dados da Rais/MTE/2003 (BRASIL, 2003) de forma a considerar apenas firmas com mais de dez empregados, $\mathrm{o}$ número de firmas se aproxima ao da Pintec, com exceção da indústria de móveis e madeira, em que os níveis de empregados apresentaram diferenças de cerca de $40 \%$ em Joaçaba e São Bento do Sul.
O segundo procedimento foi (ii) calcular a importância do emprego local para o setor no Estado e o critério mínimo de 2,5\% ${ }^{4}$

Foi considerado em terceiro e quarto lugares (iii) a relevância do emprego do setor na microrregião, e (iv) a densidade das atividades produtivas no local. Nesses procedimentos, foram aplicados critérios diferentes para os setores considerando-se a intensidade do uso de mão-de-obra na atividade industrial e as características dos processos produtivos, seus reflexos sobre a diversificação e a densidade da estrutura produtiva no local. No caso dos produtores de bens de consumo (móveis, madeira, cerâmica, têxtil-confecções, couro-calçados e alimentos), a participação do emprego no total da microrregião deveria ser superior a $1,5 \%$ e o número mínimo de 25 empresas, já que apresentam menor diversidade de segmentos produtivos e maior concentração de firmas no principal segmento da cadeia. No que concerne aos produtores de insumos e bens de capital (eletro-metalmecânico, plástico e borracha, atividades de informática e produtos químicos), a participação do emprego no total da microrregião não poderia ser menor que $0,6 \%$ e de 50 empresas, visto que apresentam maior diversidade de segmentos produtivos no local.

Nos dois procedimentos finais, procurou-se dimensionar os limites da aglome- ração em análise: (v) sob o ponto de vista setorial, os limites foram dados pela agregação das empresas pertencentes às divisões da CNAE de um mesmo ramo produtivo, e, sob o ponto de vista dos limites geográficos, (vi) foi considerado integrante de uma mesma aglomeração o conjunto das empresas inseridas em aglomerações selecionadas pelos procedimentos anteriores e que estivessem localizadas em municípios contíguos.

O resultado da aplicação desses procedimentos e critérios foi a seleção de 32 aglomerações que serviram de base para o pedido de tabulação especial dos dados da Pintec.

\subsection{Compatibilização dos resultados da seleção das aglomerações (Rais) e as informações da tabulação especial da Pintec}

As tabulações especiais da Pintec solicitadas não possibilitaram informações que correspondessem às mesmas 32 aglomerações industriais identificadas, uma vez que a agregação dos dados no nível de microrregiões e de setores industriais selecionados gerava informações que, pelas características da amostra nacional da Pintec/IBGE/2005, ${ }^{5}$ não possuíam significância estatística naquele nível de agregação. Com o objetivo de se obter infor- 
mações compatíveis com as aglomerações, adotaram-se procedimentos de agregação de divisões e microrregiões, de forma a garantir-se uma aproximação regional/ setorial adequada. O Quadro 1 mostra a correspondência entre as agregações das informações dos setores e das microrregiões feitas pela tabulação especial da Pintec/IBGE/2005 e as aglomerações industriais identificadas segundo os dados da Rais/TEM (BRASIL, 2003). Como se verifica no quadro, tal correspondência indica uma aproximação satisfatória das agregações dos dados da tabulação especial para as aglomerações.

\subsection{Variáveis e indicadores dos processos de aprendizagem}

Para a análise dos processos de aprendizagem das firmas inovadoras, foram considerados três grupos de variáveis (i) das fontes de informação utilizadas para inovar (ii) das formas de cooperação e (iii) dos dispêndios de capacitação usados pelas firmas para inovar. ${ }^{6}$

O grupo de variáveis de fontes de informação procura captar, como o próprio nome sugere, a importância dos diversos agentes como fonte de informação para as inovações realizadas pelas firmas. Revelam-se, dessa forma, características dos processos de disseminação e absorção de co- nhecimentos. Essas fontes podem ter origem interna ou externa às empresas. As primeiras dizem respeito aos "departamentos de P\&D” e também a "outras fontes internas", que incluem tanto atividades de P\&D não-rotinizadas, dispersas em departamentos ou setores cujas atividades são primordialmente de engenharia rotineira de produção e qualidade, como os setores de compras e relações com os fornecedores e mesmo os setores encarregados do marketing. As fontes externas referem-se aos fornecedores, aos clientes ou aos consumidores; aos concorrentes; às empresas de consultoria e aos consultores independentes; às universidades e aos institutos de pesquisa; aos centros de capacitação profissional e assistência técnica; às instituições de testes, ensaios e certificações, licenças, patentes e know-how; às conferências e publicações especializadas; às feiras e exposições e às redes de informação informatizadas. Os indicadores são os seguintes:

1. Importância do Departamento de P\&D e outras áreas internas: agrega as variáveis da Pintec/IBGE/ 2005 e que correspondem à avaliação da importância atribuída ao "Departamento de P\&D da empresa", a "outras áreas da empresa" e a "outras empresas do grupo";
6 O período para as variáveis referentes às fontes de informação e relações de cooperação foi de 2001 a 2003 e, para as variáveis de esforço de capacitação, que concernem a gastos das empresas, foi o último ano da pesquisa, ou seja, 2003. 
Quadro 1_ Representatividade das aglomerações em relação à tabulação especial da Pintec

\begin{tabular}{|c|c|c|c|c|}
\hline & $\begin{array}{c}\text { Denominação } \\
\text { do espaço/divisão } \\
\text { da agregação da } \\
\text { tabulação especial } \\
\text { Pintec }\end{array}$ & $\begin{array}{c}\text { Divisões/CNAE e microrregiões } \\
\text { incluídas na tabulação } \\
\text { especial Pintec }\end{array}$ & $\begin{array}{c}\text { Divisões/CNAE e microrregiões } \\
\text { segundo dados da Rais/MTE }\end{array}$ & $\begin{array}{l}\text { Representatividade das } \\
\text { aglomerações produtivas em } \\
\text { relação à agregação da } \\
\text { tabulação especial } \\
\text { (\% do número de } \\
\text { estabelecimentos) }\end{array}$ \\
\hline 1) & $\begin{array}{l}\text { Têxtil-vestuarista } \\
\text { de Blumenau }\end{array}$ & $\begin{array}{l}\text { Divisões: Têxtil e confecções } \\
\text { Microrregiões: Blumenau, } \\
\text { Rio do Sul e Ituporanga }\end{array}$ & $\begin{array}{l}\text { Divisões: Têxtil e confecções } \\
\text { Microrregiões: Blumenau, } \\
\text { Rio do Sul e Ituporanga }\end{array}$ & 100 \\
\hline 2) & $\begin{array}{l}\text { Têxtil-vestuarista } \\
\text { de Joinville }\end{array}$ & $\begin{array}{l}\text { Divisões: Têxtil e confecções } \\
\text { Microrregião: Joinville }\end{array}$ & $\begin{array}{l}\text { Divisões: Têxtil e confecções } \\
\text { Microrregião: Joinville }\end{array}$ & 100 \\
\hline 3) & $\begin{array}{l}\text { Têxtil-vestuarista } \\
\text { da região Sul }\end{array}$ & $\begin{array}{l}\text { Divisões: Têxtil e confecções } \\
\text { Microrregiões: Criciúma, } \\
\text { Tubarão e Araranguá }\end{array}$ & $\begin{array}{l}\text { Divisões: Confecções } \\
\text { Microrregiões: Criciúma, } \\
\text { Tubarão e Araranguá }\end{array}$ & 87 \\
\hline 4) & $\begin{array}{l}\text { Eletro-metal-mecânica } \\
\text { de Joinville }\end{array}$ & $\begin{array}{l}\text { Divisões: Instrumentação; outros } \\
\text { equipamentos de transporte; } \\
\text { metalurgia básica; fabricação de } \\
\text { M\&E; montagem de veículos; } \\
\text { metais exclusive M\&E } \\
\text { Microrregiões: Joinville } \\
\text { e São Bento do Sul }\end{array}$ & $\begin{array}{l}\text { Divisões: Instrumentação; outros } \\
\text { equipamentos de transporte; } \\
\text { metalurgia básica; fabricação de } \\
\text { M\&E; montagem de veículos; } \\
\text { metais exclusive M\&E } \\
\text { Microrregiões: Joinville } \\
\text { e São Bento do Sul }\end{array}$ & 100 \\
\hline 5) & $\begin{array}{l}\text { Eletro-metal-mecânica } \\
\text { de Blumenau }\end{array}$ & $\begin{array}{l}\text { Divisões: Instrumentação; outros } \\
\text { equipamentos de transporte; } \\
\text { metalurgia básica; fabricação de } \\
\text { M\&E; montagem de veículos; } \\
\text { metais exclusive M\&E } \\
\text { Microrregiões: Blumenau, } \\
\text { Rio do Sul, Itajaí e Ituporanga }\end{array}$ & $\begin{array}{l}\text { Divisões: Instrumentação; outros } \\
\text { equipamentos de transporte; } \\
\text { metalurgia básica; fabricação de } \\
\text { M\&E; montagem de veículos; } \\
\text { metais exclusive M\&E } \\
\text { Microrregiões: Blumenau } \\
\text { e Rio do Sul }\end{array}$ & 59 \\
\hline
\end{tabular}


Quadro 1_ Representatividade das aglomerações em relação à tabulação especial da Pintec

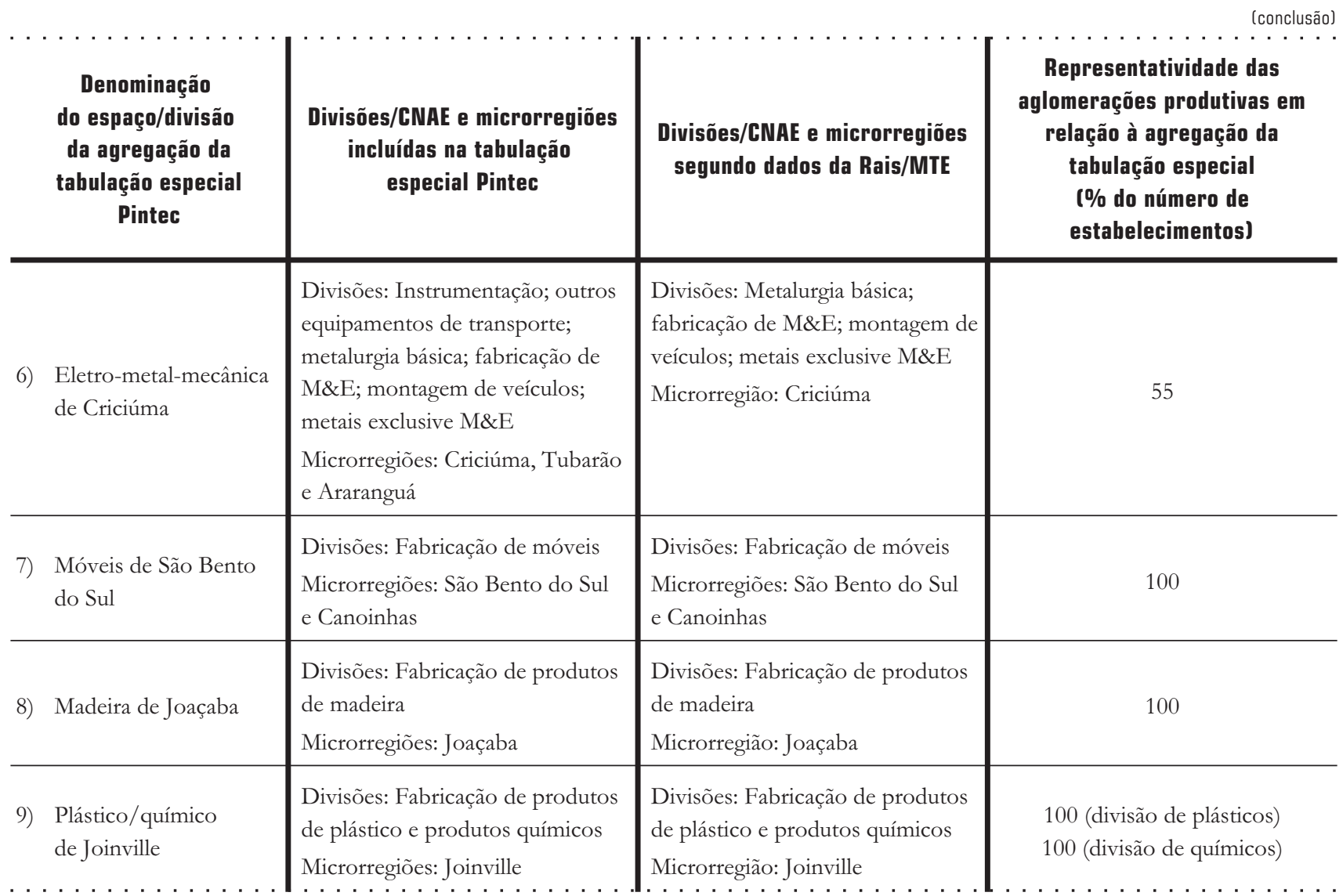

Fonte: Elaboração própria.

2. Importância das instituições de C\&T: avalia a relevância atribuída pelas empresas às informações obtidas em "universidades", "centros de capacitação e institutos de ensaios e testes";

3. Importância de outras fontes externas: avalia a relevância atribuída 
pelas empresas à obtenção de informações em fontes como "conferências e encontros", "publicações especializadas" e "empresas de consultoria";

4. Importância dos fornecedores: avalia a relevância atribuída pelas empresas às informações obtidas dos fornecedores;

5. Importância dos clientes e dos consumidores: avalia a relevância atribuída pelas empresas na obtenção de informações com seus clientes e consumidores;

6. Importância dos concorrentes: avalia a relevância atribuída pelas empresas às informações obtidas de seus concorrentes; e

7. Licenças, patentes e know-bow: avaliam a relevância atribuída pelas empresas na obtenção de informações mediante fontes de licenças, patentes e know-how.

Quanto às formas de cooperação, a Pintec/IBGE/2005 definiu a atividade pela participação em projetos conjuntos de P\&D e outros projetos de inovação com empresas ou instituições, o que não implicaria, necessariamente, benefícios comerciais imediatos. A simples contratação de serviços de outra organização, sem a sua colaboração ativa, não é considerada coo- peração. Os parceiros compartilham recursos para o desenvolvimento do projeto (IBGE, 2005).

Os agentes considerados foram os seguintes: clientes ou consumidores, fornecedores, concorrentes, outra empresa do grupo, empresas de consultoria, universidades e institutos de pesquisa e centros de capacitação profissional, conforme os indicadores a seguir:

8. Importância da cooperação vertical: relevância da cooperação atribuída pelas empresas com os "clientes ou consumidores" e com seus "fornecedores";

9. Importância da cooperação horizontal: relevância da cooperação atribuída pelas empresas com seus concorrentes;

10. Importância da cooperação institucional em C\&T: relevância atribuída pelas empresas com a cooperação com "universidades" e com "centros de capacitação técnica".

Os dispêndios para capacitação tecnológica realizados pelas empresas procuram avaliar o direcionamento dos gastos em atividades de inovação traduzidos como esforços internos e externos de aprendizagem. São expressos pelos gastos internos em P\&D, os gastos com a aquisição externa de P\&D, e de outros conhecimen- 
tos externos. ${ }^{7}$ Referem-se também à aquisição de máquinas e equipamentos, treinamento, introdução de inovações tecnológicas no mercado e em projeto industrial e outros tipos de preparação técnica, como se segue:

11. Gastos médios com P\&D e conhecimentos externos à empresa: ${ }^{8}$ avalia o esforço de capacitação das firmas associado à "aquisição de P\&D externos" e de "outros conhecimentos externos";

12. Gastos médios com P\&D internos à empresa: avalia os esforços internos de capacitação das empresas inovadoras relacionados à geração de inovações em seus "departamentos internos de P\&D";

13. Gastos médios na aquisição de máquinas e equipamentos: procura avaliar o esforço de atualização tecnológica associado à aquisição de máquinas e equipamentos;

14. Gastos médios internos no desenvolvimento de projetos industriais e outros tipos de preparação técnica: procura avaliar os gastos internos das empresas relacionados ao desenvolvimento de projetos industriais e outros tipos de preparação técnica nas fases finais do processo de inovação.

\section{4_Procedimentos para a construção dos indicadores}

Pela necessidade de transformar os atributos qualitativos da Pintec em atributos quantitativos, " para a análise estatística, procurou-se ponderar valores que traduzissem a avaliação das empresas a respeito das formas de cooperação e da importância do uso das fontes de informação para inovação. Para esses dois grupos de indicadores, foram definidas as seguintes ponderações: as respostas que classificavam a importância do uso da fonte, ou da forma de cooperação como alta, foram multiplicadas por "1"; as classificadas como média foram multiplicadas por " 0,6 "; e as classificadas como baixa relevância foram multiplicadas por " 0,2 ". A soma das respostas multiplicadas pelos valores

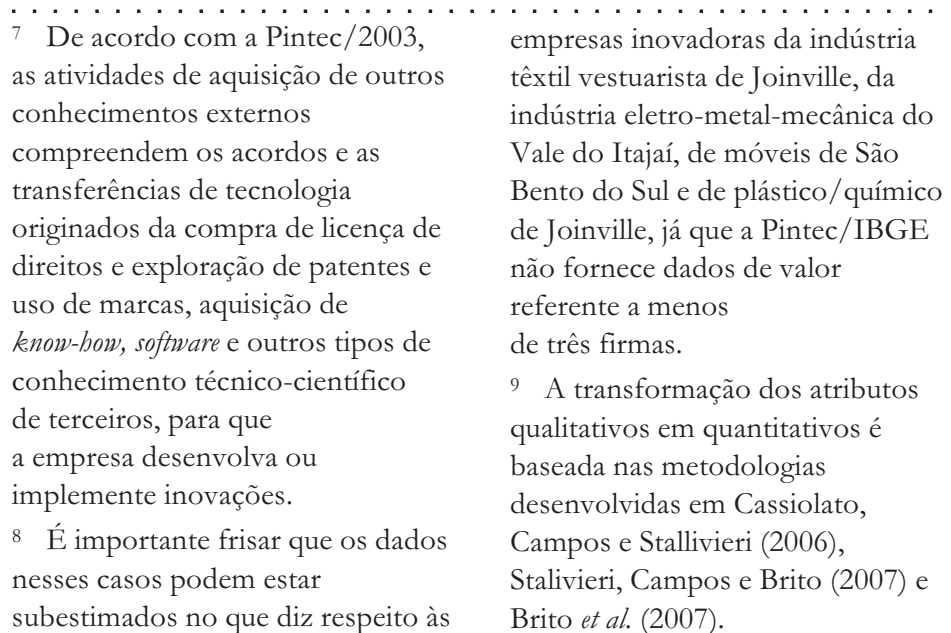


referidos e divididos pelo número total de respostas para o quesito resultava num índice cujo valor mais próximo de 1 indicava maior importância atribuída pela empresa àquele quesito. ${ }^{10}$

No que se refere aos indicadores de dispêndio ${ }^{11}$ para capacitação tecnológica, esses foram calculados com base na média dos gastos realizados pelas firmas inovadoras.

Na seção que se segue, são analisados os dados que resultaram desses procedimentos e que caracterizam a aprendizagem tecnológica nas aglomerações produtivas catarinenses. Além disso, comparam-se as taxas de inovação das aglomerações com a de Santa Catarina e a do Brasil.

\section{4_Aprendizagem tecnológica e inovação em aglomerações catarinenses}

Os dados da Pintec mostram que, das 2.824 empresas inseridas nas aglomerações pesquisadas, 1.032 inovaram (36,5\%). Segun-

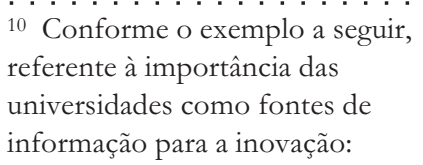

11 Os indicadores de dispêndio tecnológico são medidos em "mil R\$”. do informações da Tabela 1, das nove aglomerações consideradas, seis apresentaram taxas de inovação superiores à brasileira. Entre essas, a taxa de inovação mostrou-se muito superior à catarinense no têxtil/vestuário e eletro-metal-mecânico em Joinville, e em Criciúma também no setor eletro-metal-mecânico.

Os gastos totais superaram os $\mathrm{R} \$ 380$ milhões. A aquisição de máquinas e equipamentos como forma de incorporação de novas tecnologias é tipo de gasto mais freqüente e foi realizada por 623 das empresas. Ao lado desse tipo de gasto, as empresas inovadoras catarinenses, em menor número (219), realizaram também gastos mais específicos com atividades internas de $\mathrm{P} \& \mathrm{D}$, o que sugere a existência de rotinas de aprendizagem para inovação que incluem esforços que vão além das práticas realizadas estritamente no âmbito da produção.

Como destacam o Gráfico 1 e a Tabela 2 a seguir, os gastos em P\&D mais sistemáticos estão concentrados nos setores da eletro-metal-mecânica, plástico e químico e têxtil-vestuário na região de Joinville e no setor têxtil-vestuário de Blumenau. Também o setor de móveis de São Bento do Sul realiza esforço interno de capacitação, mas em menor escala e por um número menor de firmas (Tabela 2). 
Tabela 1_Firmas pesquisadas, firmas inovadoras e taxa de inovação nas aglomerações catarinenses

\begin{tabular}{|c|c|c|c|c|c|c|c|c|c|c|c|c|}
\hline \multirow{2}{*}{ Aglomerações/Local } & \multicolumn{3}{|c|}{ Têxtil-vestuarista } & \multicolumn{3}{|c|}{ Eletro-metal-mecânica } & \multirow{2}{*}{$\begin{array}{c}\text { Móveis } \\
\begin{array}{c}\text { São } \\
\text { Bento } \\
\text { do Sul }\end{array}\end{array}$} & \multirow{2}{*}{$\begin{array}{l}\text { Madeira } \\
\text { Joaçaba }\end{array}$} & \multirow{2}{*}{$\begin{array}{l}\text { Plástico/ } \\
\text { Químico }\end{array}$} & \multicolumn{3}{|c|}{ Total } \\
\hline & $\begin{array}{c}\text { Blume- } \\
\text { nau }\end{array}$ & Joinville & $\begin{array}{l}\text { Região } \\
\text { Sul }\end{array}$ & Joinville & $\begin{array}{c}\text { Blume- } \\
\text { nau }\end{array}$ & $\begin{array}{c}\text { Criciú- } \\
\text { ma }\end{array}$ & & & & $\begin{array}{l}\text { Da } \\
\text { amostra }\end{array}$ & $\begin{array}{l}\text { Santa } \\
\text { Catarina }\end{array}$ & Brasil \\
\hline Número total de firmas & 1.059 & 235 & 331 & 331 & 321 & 122 & 199 & 124 & 103 & 2.824 & 6.915 & 84.262 \\
\hline $\begin{array}{l}\text { Número total de firmas } \\
\text { inovadoras }\end{array}$ & 370 & 141 & 75 & 157 & 114 & 71 & 70 & 11 & 23 & 1.032 & 2.480 & 28.036 \\
\hline Taxa de inovações & 34,4 & 60 & 22,3 & 47,4 & 35,5 & 58,2 & 35,2 & 8,9 & 22,3 & 36,5 & 35,5 & 33,3 \\
\hline
\end{tabular}

Fonte: Elaboração própria com base na tabulação especial da Pintec.

Gráfico 1_ Dispêndios médios em capacitação tecnológica das firmas inovadoras locais (em mil R\$)

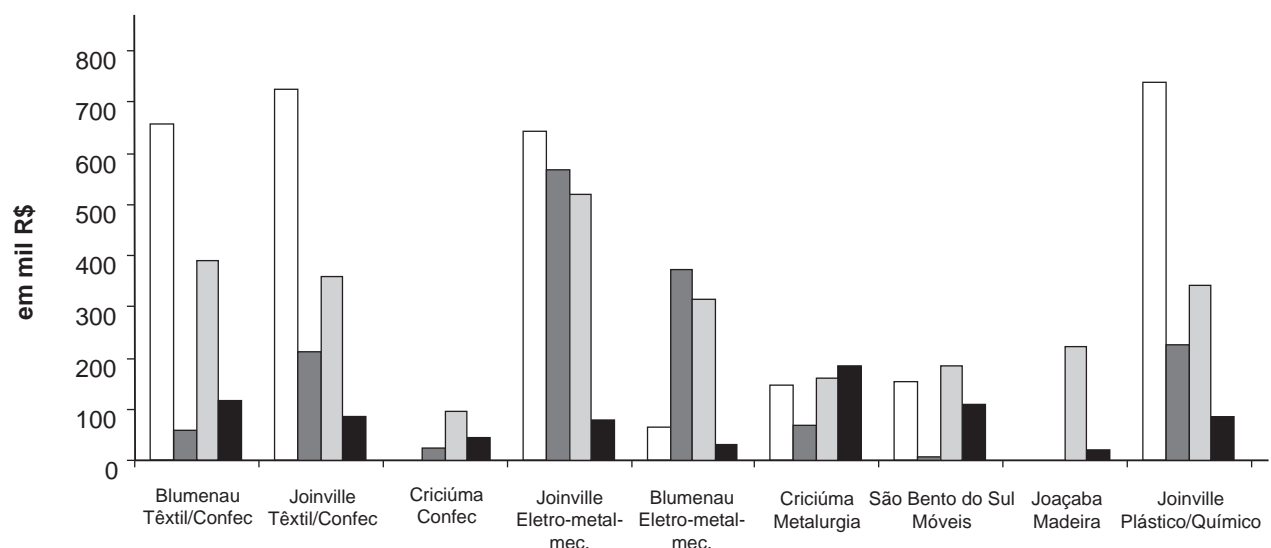
$\square$ Gastos médios P\&D interna
$\square$ Gastos médios P\&D e conhecimentos externos
$\square$ Gasto médio na aquisição de M\&E
- Gasto médio em projetos e preparações técnicas

Fonte: Elaboração própria com base na tabulação especial da Pintec/IBGE/2005. 
Tabela 2_Dispêndios em atividades inovadoras nas aglomerações industriais catarinenses

\begin{tabular}{|c|c|c|c|c|c|c|c|c|c|c|c|c|}
\hline \multirow[t]{2}{*}{ Aglomerações } & \multicolumn{2}{|c|}{$\begin{array}{l}\text { Total de firmas } \\
\text { inovadoras que } \\
\text { realizaram algum } \\
\text { dispêndio em } \\
\text { inovação' }\end{array}$} & \multicolumn{2}{|c|}{$\begin{array}{c}\text { Atividades internas } \\
\text { de P\&D }\end{array}$} & \multicolumn{2}{|c|}{$\begin{array}{l}\text { Aquisição externa } \\
\text { de P\&D }\end{array}$} & \multicolumn{2}{|c|}{$\begin{array}{l}\text { Aquisição de } \\
\text { outros } \\
\text { conhecimentos } \\
\text { externos }\end{array}$} & \multicolumn{2}{|c|}{ Aquisição de M\&E } & \multicolumn{2}{|c|}{$\begin{array}{l}\text { Projeto industrial } \\
\text { e outras } \\
\text { preparações } \\
\text { técnicas }\end{array}$} \\
\hline & $\begin{array}{c}N^{0} \\
\text { firmas }\end{array}$ & $\begin{array}{c}\text { Valor } \\
\text { (1.000 R\$) }\end{array}$ & $\begin{array}{c}N^{0} \\
\text { firmas }\end{array}$ & $\begin{array}{l}\% \text { do } \\
\text { gasto }\end{array}$ & $\begin{array}{c}N^{0} \\
\text { firmas }\end{array}$ & $\begin{array}{l}\% \text { do } \\
\text { gasto }\end{array}$ & $\begin{array}{c}N^{0} \\
\text { firmas }\end{array}$ & $\begin{array}{l}\% \text { do } \\
\text { gasto }\end{array}$ & $\begin{array}{c}N^{0} \\
\text { firmas }\end{array}$ & $\begin{array}{l}\% \text { do } \\
\text { gasto }\end{array}$ & $\begin{array}{c}N^{0} \\
\text { firmas }\end{array}$ & $\begin{array}{l}\% \text { do } \\
\text { gasto }\end{array}$ \\
\hline $\begin{array}{l}\text { Blumenau/Têxtil } \\
\text { Confecções }\end{array}$ & 239 & 141.916 & 42 & 19,30 & 33 & 0,89 & 67 & 3,76 & 207 & 56,93 & 112 & 9,30 \\
\hline $\begin{array}{l}\text { Joinville/Têxtil } \\
\text { Confecções }\end{array}$ & 92 & 32.435 & 10 & 22,50 & 1 & $\mathrm{x}$ & 4 & 5,29 & 52 & 57,43 & 9 & 2,22 \\
\hline $\begin{array}{l}\text { Criciúma/Têxtil } \\
\text { Confecções }\end{array}$ & 69 & 8.788 & 0 & - & 0 & - & 3 & 1,83 & 66 & 72,04 & 7 & 3,65 \\
\hline $\begin{array}{l}\text { Joinville/Eletro- } \\
\text { Metal-Mecânica }\end{array}$ & 140 & 114.553 & 63 & 35,60 & 6 & 4,42 & 17 & 4,94 & 102 & 46,26 & 82 & 5,60 \\
\hline $\begin{array}{l}\text { Blumenau/Eletro-Metal- } \\
\text { Mecânica }\end{array}$ & 103 & 28.581 & 56 & 12,51 & 1 & $\mathrm{x}$ & 4 & 6,50 & 61 & 67,07 & 51 & 5,77 \\
\hline $\begin{array}{l}\text { Criciúma/Eletro- } \\
\text { Metal-Mecânica }\end{array}$ & 71 & 21.636 & 28 & 19,02 & 0 & - & 8 & 2,55 & 53 & 39,76 & 39 & 33,15 \\
\hline $\begin{array}{l}\text { Móveis/São Bento } \\
\text { do Sul }\end{array}$ & 65 & 18.444 & 11 & 9,21 & 2 & $\mathrm{x}$ & 5 & 0,45 & 64 & 64,77 & 34 & 20,10 \\
\hline Madeira/Joaçaba & 4 & 983 & 0 & - & 0 & - & 0 & - & 4 & 92,24 & 3 & 6,24 \\
\hline $\begin{array}{l}\text { Plástico/Joinville } \\
\text {. . . . . . . . } \\
\text { x = Informação sigilosa. }\end{array}$ & 17 & 16.173 & 9 & 39,32 & 1 & $\mathrm{x}$ & 3 & $\begin{array}{c}8,99 \\
.\end{array}$ & $\begin{array}{l}13 \\
.\end{array}$ & $\begin{array}{l}27,24 \\
\therefore .\end{array}$ & $\begin{array}{l}5 \\
.\end{array}$ & $\begin{array}{l}2,79 \\
\cdots\end{array}$ \\
\hline
\end{tabular}


Além disso, em todas as aglomerações, parte do esforço inovador refere-se a gastos com "projetos industriais e outras preparações técnicas", ainda que em níveis mais reduzidos e com certo destaque para a aglomeração na eletro-metal-mecânica no Sul do Estado.

Já o indicador de gastos em P\&D e a aquisição de outros conhecimentos externos apresentam relevância, sobretudo nos casos localizados em Joinville, e da atividade eletro-metal mecânica em Blumenau, o que é característico de um setor de maior complexidade tecnológica, e aponta a presença de competências internas de firmas para selecionar e absorver conhecimentos gerados externamente.

Considerando os indicadores de cooperação, o ponto a ser destacado é que, conforme se observa no Gráfico 2, as firmas inseridas em quatro das nove aglomerações produtivas não apresentaram nenhum tipo de relação de cooperação. Além disso, no caso da aglomeração de plástico/química de Joinville, a resposta para esse quesito é de apenas uma empresa, o que na prática amplia o número de aglomerações sem cooperação para cinco das nove consideradas. Nas aglomerações onde há cooperação, maior importância é atribuída a relacionamentos verticais, ou seja, com fornecedores e consumidores, o que, por um lado, aponta inovações de caráter adaptativo e incre- mental, e, por outro, vantagens locais geradas pela proximidade entre esses agentes.

Às relações de cooperação horizontal e às instituições de C\&T é atribuída menor importância. Novamente excluiu-se a aglomeração de plástico/química em Joinville pelo motivo já apontado. No entanto, ainda que em graus mais reduzidos de importância, essas relações, ao indicarem a presença de práticas cooperativas entre concorrentes e com instituições de C\&T, sugerem a ação de agentes associativos e de entidades de ciência e tecnologia local que estimula as atividades de inovação.

Quanto ao grupo de indicadores que avalia a importância atribuída pelas firmas ao uso das fontes de informação para a inovação (ver Gráfico 3), observa-se novamente maior relevância das que ocorrem por relações de mercados, quais sejam: com os consumidores, com os setores produtores de insumos e bens de capital para essas indústrias, e com os concorrentes.

A exemplo da prática recorrente do Sistema Nacional de Inovações brasileiro, em que prevalecem a absorção e a adaptação de tecnologias já testadas (Coutinho e Ferraz, 1995), a importância das fontes de informação advindas das instituições de C\&T ou de licenças, patentes e know-how é reduzida. Esses indicadores situam-se entre 0,20 e 0,32 . 
Gráfico 2_ Indicadores das formas de cooperação utilizadas pelas empresas inovadoras

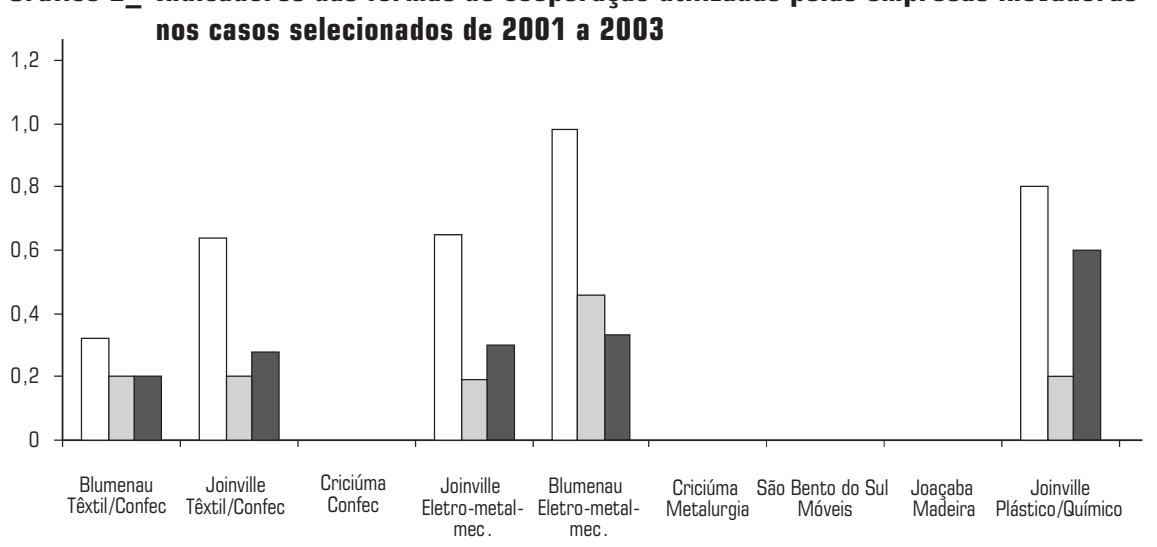

$\square$ Cooperação vertical $\square$ Cooperação horizontal $\square$ Cooperação institucional de C\&T

Fonte: Elaboração própria com base na tabulação especial da Pintec/IBGE/2005.

\section{Gráfico 3_ Intensidade das formas de cooperação utilizadas pelas empresas inovadoras} dos casos selecionados de 2001 a 2003

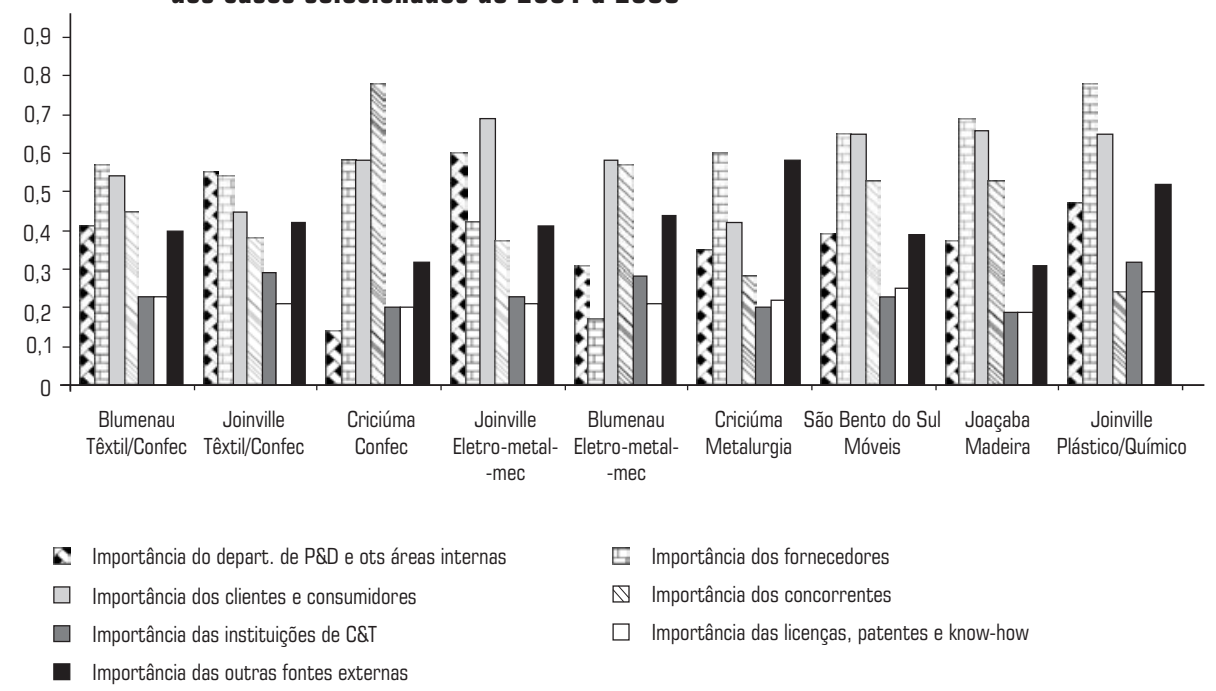

Fonte: Elaboração própria com base na tabulação especial da Pintec/IBGE/2005. 
Os resultados dos indicadores do uso de fontes de informações para a inovação, apesar de não identificarem a localização dessas, sugerem, pela grande importância das fontes relacionadas à ação das empresas no mercado, que é relevante para a ação inovadora a inserção das empresas em aglomerações produtivas mais densas, na medida em que estabelecem melhores condições para a criação de vantagens sistêmicas específicas nessas regiões.

Resumidamente, observou-se que, junto com a menor atribuição de importância às fontes relacionadas ao sistema mais específico de ciência e tecnologia, parte significativa de firmas realiza esforços internos de capacitação, como foi observado no grupo dos indicadores referentes aos gastos com inovação. E esse esforço demonstra que o uso de fontes de informação mais relacionadas à ação das empresas no mercado está se traduzindo em capacitação interna importante. Essa afirmação é corroborada pelos indicadores de importância atribuídos ao uso das informações geradas internamente pelas empresas (importância do uso de P\&D e conhecimentos internos), cujo mínimo foi de 0,14 e o máximo de 0,59 .

De modo geral, pode-se afirmar que o uso das fontes de informação que decorre da ação das empresas nos mercados, das relações verticais de cooperação, aliadas aos baixos valores dos indicadores de uso de fontes externas institucionais de C\&T e à alta freqüência na aquisição de máquinas e equipamentos, está apontando que as inovações tecnológicas locais são novas apenas para as empresas e relacionadas a adaptações e pequenas modificações.

\section{5_ As semelhanças e as distinções dos processos de aprendizagem nas aglomerações produtivas selecionadas}

Para indicar as características principais dos processos de aprendizagem comuns a certos grupos de casos, optou-se por agrupar os casos mais semelhantes, segundo os indicadores formados mediante a técnica estatística de análise multivariada de cluster ou agrupamento, que faz parte de um conjunto de técnicas exploratórias de dados, as quais, por meio de gráficos e/ou de caracterização de dados, possibilitam a identificação de semelhanças nos processos de aprendizagem.

A análise de cluster permite a classificação de "casos", sendo que não se conhece, a priori, os grupos que se formarão, nem mesmo seu número. Trata-se, portanto, de uma técnica cujo fim é a formação de grupos mais homogêneos possíveis, respeitando a distribuição dos valores das variáveis con- 
sideradas. Para este trabalho, os "casos" são as empresas inovadoras inseridas nas aglomerações produtivas selecionadas, e as variáveis são os indicadores construídos.

Para que se possa executar a técnica, deve-se definir anteriormente o método de formação dos grupos e o tipo de distância que se vai considerar. O software statistica oferece várias opções. Para a formação dos grupos, optou-se pelo método do vizinho mais distante, ou complete linkages, que forma os grupos através das distâncias mínimas dos casos mais distantes. Para as distâncias, foram utilizadas as "euclidianas" entre os casos, que, obviamente, são bastante influenciadas pelas unidades de medida das variáveis. Considerando que as variáveis de dispêndio em capacitação tecnológica são medidas por valores monetários (mil $\mathrm{R} \$$ ), enquanto as de cooperação e uso de fontes de informação são medidas pelos índices que variam de "0 a 1", foi necessária a padronização das variáveis, de forma a torná-las com média igual a " 0 " e desvio padrão igual a "1".

O dendograma a seguir mostra as ligações (linkages) formadas nos nove casos selecionados.

\section{Gráfico 4_ Agrupamento das empresas inovadoras nas aglomerações produtivas selecionadas, conforme os indicadores da dinâmica tecnologia construídos}

Tree Diagram for 9 Cases/Complete Linkage/Euclidean distances

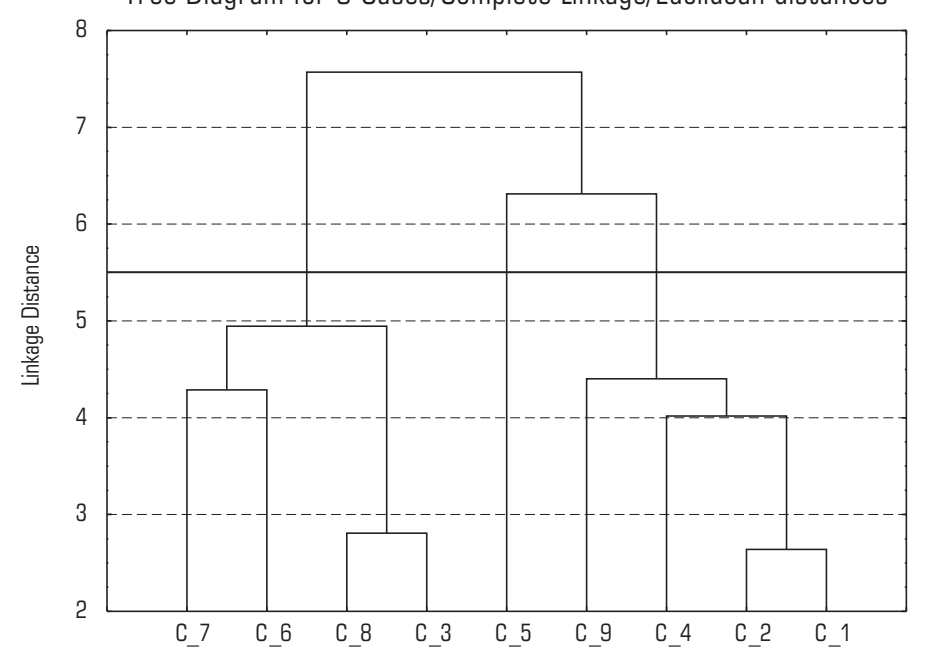

Fonte: Software statistica, com base em informações da Pintec/IBGE/2005. 
A linha traçada no ponto 5,5 do eixo vertical destaca a formação de três agrupamentos (clusters). Da esquerda para a direita, o primeiro cluster é formado pelas firmas inovadoras das aglomerações produtivas, moveleira de São Bento do Sul (C_7), metal-mecânica de Criciúma (C_6), madeireira de Joaçaba (C_8) e têxtil-vestuarista de Criciúma (C_3); o segundo clusteré formado somente pelo caso das empresas inovadoras da indústria eletro-metal-mecânica de Blumenau (C_5); e o cluster três é formado pelas firmas inovadoras da indústria plástico/química (C_9), eletro-metal-mecânica (C_4) e têxtil/vestuarista de Joinville (C_2) e têxtil/vestuarista de Blumenau (C_1).

Foram determinantes para a formação desses grupos as formas de relação cooperativa utilizadas e os dispêndios em capacitação tecnológica, já que o uso de fontes de informação para a inovação não apresenta discrepâncias fundamentais entre os três agrupamentos (Gráficos 1, 2 e 3).

\subsection{Setores e locais de baixo dinamismo tecnológico: eletro-metal-mecânica e têxtil-confecções em Criciúma, móveis em São Bento do Sul e madeira em Joaçaba}

De forma geral, o cluster1 agrupa empresas inovadoras de setores de tecnologia difundida e, em alguns casos, localizados em estruturas produtivas de formações históricas recentes, nos quais as relações de aprendizagem são mais restritas, bem como é reduzido o dispêndio com atividades de capacitação e inexistem relações de cooperação ${ }^{12}$ para inovação. Trata-se, portanto, de um agrupamento no qual as empresas inovadoras apresentam "baixo dinamismo tecnológico".

Nesse agrupamento, estão incluídos os setores de metalurgia básica e produtos de metal (C_6) e confecções (C_3) localizados na microrregião de Criciúma e a indústria de móveis localizada na microrregião de São Bento do Sul (C_7) e madeireira em Joaçaba (C_8).

Observando-se as maiores ligações formadas pelo método do vizinho mais distante mostrado no Gráfico 4, percebe-se a semelhança de comportamento das empresas inovadoras do setor de madeira localizado em Joaçaba (C_8) e do setor têxtil/ confecções localizado em Criciúma (C_3), cujos esforços de capacitação restringem-se, praticamente, à aquisição de máquinas e equipamentos (Gráfico 1).

A formação do cluster mostrou também ligações entre os casos de móveis em São Bento do Sul (C_7) e da atividade metal-mecânica, em Criciúma (C_6), explicada pela semelhança nos níveis de dispêndios em inovação para a aquisição de máquinas e equipamentos, seguidos por gastos em pro-

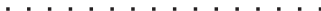

12 Ainda que, pelo menos em São Bento do Sul, várias práticas, como a aquisição conjunta de matéria-prima, já tenham sido implementadas, até com forte apoio de instituições formais locais, como o sindicato patronal e a associação industrial. Contudo, práticas oportunistas parecem ter sido decisivas para a descrença dos empresários nesse tipo de estratégia (Denk, 2002). 
jetos industriais e em atividades de P\&D internos. No que diz respeito a São Bento do Sul, estudos demonstraram que os gastos se referem ao desenvolvimento de designs (Denk, 2002). Já na atividade metal-mecânica de Criciúma, esses gastos podem ser explicados pela existência no local de um segmento produtor de máquinas e equipamentos.

Nos casos localizados na microrregião de Criciúma, tanto a maturidade tecnológica dos setores quanto a formação recente da estrutura industrial local podem explicar os processos de aprendizagem menos dinâmicos.

Em Joaçaba e São Bento do Sul, a importância dada pelas firmas às fontes de informação verticais - clientes, consumidores e fornecedores -, combinada aos dispêndios com a aquisição de máquinas e equipamentos, é estimulada pela presença de firmas produtoras de máquinas e equipamentos nos locais (Bittencourt, 2006). Nesses, percebeu-se alguma relevância no uso das informações originadas pelos concorrentes e em menor medida de fontes internas de informação. O primeiro caso está, possivelmente, associado a práticas de imitação, dada a ampla difusão dos conhecimentos técnicos necessários à produção de móveis e artigos de madeira. Já as fontes internas podem estar associadas à internali- zação na firma de diversas fases do processo de produção.

Nesse cluster, estão agrupados, portanto, os setores/locais nos quais inexistem relações de cooperação para inovação, e a importância atribuída pelas empresas inovadoras ao uso de fontes de informação se restringe àquelas relações que decorrem das práticas de produção e vendas, quais sejam, relações com fornecedores, clientes e concorrentes. Em tal cluster, os dispêndios em capacitação tecnológica se referem principalmente à aquisição de máquinas e equipamentos, e em menor medida aos gastos com o desenvolvimento de projetos e outros tipos de preparação técnica.

\section{2_ Setores e locais de médio dinamismo tecnológico: o setor eletro-metal-mecânico de Blumenau}

O cluster 2 caracteriza um conjunto intermediário entre os três agrupamentos identificados e inclui apenas um aglomerado, que é o setor eletro-metal-mecânico da microrregião de Blumenau (C_5); esse, juntamente com Joinville, foi um importante núcleo de origem do processo de industrialização catarinense e apresenta alta diversificação da estrutura industrial. 
Tabela 3_ Indicadores dispêndios em atividades de inovação, das fontes de informação e das formas de cooperação nas aglomerações de baixo dinamismo tecnológico

\begin{tabular}{|c|c|c|c|c|c|}
\hline & Indicadores & $\begin{array}{c}\text { São Bento } \\
\text { do Sul/Móveis }\end{array}$ & $\begin{array}{l}\text { Joaçaba/ } \\
\text { Madeira }\end{array}$ & $\begin{array}{l}\text { Criciúma/ } \\
\text { Metalúrgico }\end{array}$ & $\begin{array}{l}\text { Criciúma/ } \\
\text { Confecções }\end{array}$ \\
\hline \multirow{3}{*}{$\begin{array}{l}\text { Dispêndio } \\
\text { em capacitação } \\
\text { tecnológica }\end{array}$} & Gasto médio com P\&D interno & 155,17 & 0,00 & 147,01 & 0,00 \\
\hline & $\begin{array}{l}\text { Gasto médio com P\&D } \\
\text { e conhecimentos externos }\end{array}$ & 7,79 & 0,00 & 68,85 & 24,03 \\
\hline & $\begin{array}{l}\text { Gasto médio no desenvolvimento de } \\
\text { projetos e preparação técnica }\end{array}$ & 107,86 & 20,00 & 183,83 & 43,16 \\
\hline \multirow{3}{*}{$\begin{array}{l}\text { Estratégias } \\
\text { de cooperação }\end{array}$} & Importância da cooperação vertical & 0,00 & 0,00 & 0,00 & 0,00 \\
\hline & $\begin{array}{l}\text { Importância da cooperação } \\
\text { horizontal }\end{array}$ & 0,00 & 0,00 & 0,00 & 0,00 \\
\hline & $\begin{array}{l}\text { Importância da cooperação } \\
\text { institucional de C\&T }\end{array}$ & 0,00 & 0,00 & 0,00 & 0,00 \\
\hline \multirow{6}{*}{$\begin{array}{l}\text { Fontes de informação } \\
\text { à inovação }\end{array}$} & $\begin{array}{l}\text { Importância do Departamento } \\
\text { de P\&D e outras áreas internas }\end{array}$ & 0,39 & 0,37 & 0,35 & 0,14 \\
\hline & Importância dos fornecedores & 0,65 & 0,69 & 0,60 & 0,58 \\
\hline & $\begin{array}{l}\text { Importância dos clientes } \\
\text { e consumidores }\end{array}$ & 0,65 & 0,66 & 0,42 & 0,58 \\
\hline & Importância dos concorrentes & 0,53 & 0,53 & 0,28 & 0,78 \\
\hline & $\begin{array}{l}\text { Importância das instituições } \\
\text { de C\&T }\end{array}$ & 0,23 & 0,19 & 0,20 & 0,20 \\
\hline & $\begin{array}{l}\text { Importância das licenças, } \\
\text { patentes e know -how }\end{array}$ & 0,25 & 0,19 & 0,22 & 0,20 \\
\hline
\end{tabular}

Fonte: Elaboração própria com base na tabulação especial da Pintec/IBGE. 
As características dos processos de aprendizagem das firmas inovadoras desse agrupamento são semelhantes às do primeiro agrupamento, em virtude dos níveis incipientes de gastos médios com a atividade inovativa em P\&D interna e em projetos industriais e outros tipos de preparação técnica. Por outro lado, como no terceiro agrupamento (apresentado a seguir), também realiza gastos com a aquisição de $\mathrm{P} \& \mathrm{D}$ e outros conhecimentos externos. Além de existirem estratégias de cooperação semelhantes, com destaque para a importância atribuída à cooperação vertical.
As ligações apresentadas no Gráfico 4 entre esse cluster e o cluster 3 sugerem maiores semelhanças dos processos de aprendizagem. Contudo, o setor eletro-metalmecânico de Blumenau é menos denso e diversificado, segundo observado pelo número de divisões/CNAE que o de Joinville (do cluster 3).

Essas características o situam num nível intermediário em relação aos demais clusters, principalmente quanto ao nível de dispêndio em capacitação tecnológica.

Tabela 4_ Indicadores dispêndios em atividades de inovação, das fontes de informação e das formas de cooperação na aglomeração de médio dinamismo tecnológico

\begin{tabular}{|c|c|c|}
\hline Grupos de variáveis & Indicadores & $\begin{array}{l}\text { Blumenau/ } \\
\text { eletro-metal-mecânico }\end{array}$ \\
\hline \multirow{4}{*}{ Dispêndio em capacitação tecnológica } & Gasto médio com P\&D interno & 63,85 \\
\hline & Gasto médio com P\&D e conhecimentos externos & 371,25 \\
\hline & Gasto médio com aquisição de M\&E & 314,26 \\
\hline & Gasto médio no desenvolvimento de projetos e preparação técnica & 32,12 \\
\hline \multirow{3}{*}{ Estratégias de cooperação } & Importância da cooperação vertical & 0,98 \\
\hline & Importância da cooperação horizontal & 0,46 \\
\hline & Importância da cooperação institucional de C\&T & 0,33 \\
\hline \multirow{6}{*}{ Fontes de informação à inovação } & Importância do Departamento de P\&D e outras áreas internas & 0,31 \\
\hline & Importância dos fornecedores & 0,19 \\
\hline & Importância dos clientes e consumidores & 0,58 \\
\hline & Importância das instituições de C\&T & 0,28 \\
\hline & Importância das licenças, patentes e know-how & 0,21 \\
\hline & Importância das outras fontes externas & 0,44 . \\
\hline
\end{tabular}

Fonte: Elaboração própria com base na tabulação especial da Pintec/IBGE. 


\subsection{Setores e locais de alto dinamismo tecnológico: eletro-metal-mecânico, têxtil-vestuarista e plástico- químico, em Joinville, e têxtil-vestuário, em Blumenau}

Finalmente, o cluster 3 combina características locais com setoriais, diferenciando os casos das microrregiões mais industrializadas do Estado. Os três casos da microrregião de Joinville, setor eletrometal-mecânico (C_4), têxtil/vestuarista (C_2) e plástico/químico (C_9) estão nesse agrupamento com as empresas do aglomerado produtivo têxtil/vestuarista de Blumenau (C_1). O agrupamento combina os maiores valores na maioria dos indicadores. Cabe ressaltar que, de um total de 29 empresas que cooperaram de alguma maneira para a inovação, 26 se encontram nesse agrupamento, e ainda, dos $\mathrm{R} \$ 383.509 .000,00$ gastos na atividade inovativa feitos pelas empresas inovadoras dos 3 agrupamentos, $\mathrm{R} \$ 305.077 .000,00$ concentram-se no agrupamento 3. Considerando, além disso, a localização das firmas nas duas microrregiões mais industrializadas do Estado, pode-se dizer que se trata de um agrupamento de " alto dinamismo tecnológico".

Esse cluster mostra como determinantes locais podem ser fundamentais aos processos de aprendizagem de firmas inseridas em setores industriais, com diferentes dinâmicas de aprendizado. É exemplo disso o comportamento das firmas inovadoras nas indústrias têxtil/confecções e eletro-metalmecânico de Joinville.

O esforço de capacitação em P\&D interno é uma característica marcante da aprendizagem nos aglomerados desse agrupamento. Os valores com esses gastos foram em média de $\mathrm{R} \$ 650$ mil por empresa inovadora; nos demais agrupamentos, eles não passaram de R $\$ 150$ mil. ${ }^{13} \mathrm{Na}$ aquisição de máquinas e equipamentos, os gastos médios também são maiores e, além disso, as empresas inovadoras, situadas especificamente em Joinville, são as que mais investiram na aquisição de conhecimentos e P\&D externos, com níveis médios superiores a $\mathrm{R} \$ 200$ mil, destacando o setor eletro-metal-mecânico, que chegou a mais de $\mathrm{R} \$ 500$ mil em média, enquanto a maioria dos outros casos apresentou níveis próximos de " 0 " (excluindo-se as empresas da atividade eletro-metal-mecânica de Blumenau).

O uso dos Departamentos de P\&D como fontes internas de informação teve maior relevância na avaliação das empresas, já que o índice de importância variou entre 0,4 e 0,6 , ao passo que, fora desse agrupamento, a variação permaneceu em torno de 0,15 e 0,38. Ademais, as fontes de informação de C\&T também foram consideradas mais importantes pelas firmas. $\because \cdots \cdots \cdot \cdots \cdot \cdots \cdot \cdots$ 13 Este foi o caso da média de gasto das empresas inovadoras da aglomeração produtiva moveleira da microrregião de São Bento do Sul. 
Os indicadores das práticas cooperativas apresentam alta relevância nesse cluster, bem como no caso do cluster dois, o que revela a existência de ações coletivas, ainda que incipientes, exclusivamente em Blumenau e Joinville, apesar do pequeno número de firmas envolvidas.

Tabela 5_ Indicadores dispêndios em atividades de inovação, das fontes de informação e das formas de cooperação nas aglomerações de alto dinamismo tecnológico

\begin{tabular}{|c|c|c|c|c|c|}
\hline & Indicadores & $\begin{array}{c}\text { Blumenau } \\
\text { têxtil/confecções }\end{array}$ & $\begin{array}{l}\text { Joinville } \\
\text { têxtil/confecções }\end{array}$ & $\begin{array}{c}\text { Joinville } \\
\text { eletro-metal } \\
\text { mecânico }\end{array}$ & $\begin{array}{c}\text { Joinville } \\
\text { plástico/químico }\end{array}$ \\
\hline \multirow{3}{*}{$\begin{array}{l}\text { Dispêndio } \\
\text { em capacitação } \\
\text { tecnológica }\end{array}$} & Gasto médio com P\&D interno & 656,97 & 726,19 & 642,60 & 736,83 \\
\hline & Gasto médio com P\&D e conhecimentos externos & 59,21 & 213,40 & 567,86 & 225,25 \\
\hline & $\begin{array}{l}\text { Gasto médio no desenvolvimento de projetos } \\
\text { e preparação técnica }\end{array}$ & 117,33 & 84,41 & 78,26 & 86,23 \\
\hline \multirow[b]{2}{*}{$\begin{array}{l}\text { Estratégias } \\
\text { de cooperação }\end{array}$} & Importância da cooperação vertical & 0,32 & 0,64 & 0,65 & 0,80 \\
\hline & Importância da cooperação horizontal & 0,20 & 0,20 & 0,19 & 0,20 \\
\hline \multirow{7}{*}{$\begin{array}{l}\text { Fontes de } \\
\text { informação } \\
\text { à inovação }\end{array}$} & $\begin{array}{l}\text { Importância do Departamento de P\&D } \\
\text { e outras áreas internas }\end{array}$ & 0,41 & 0,55 & 0,60 & 0,47 \\
\hline & Importância dos fornecedores & 0,57 & 0,54 & 0,42 & 0,78 \\
\hline & Importância dos clientes e dos consumidores & 0,54 & 0,45 & 0,69 & 0,65 \\
\hline & Importância dos concorrentes & 0,45 & 0,38 & 0,37 & 0,24 \\
\hline & Importância das instituições de C\&T & 0,23 & 0,29 & 0,23 & 0,32 \\
\hline & Importância das licenças, patentes e know-how & 0,23 & 0,21 & 0,21 & 0,24 \\
\hline & Importância das outras fontes externas & 0,40 & 0,42 & 0,41 & 0,52 \\
\hline
\end{tabular}

Fonte: Elaboração própria com base na tabulação especial da Pintec/IBGE. 
O destaque na composição desse cluster é o setor eletro-metal-mecânico de Joinville. Os dispêndios totais em P\&D interna e externa, por exemplo, são superiores aos de qualquer outra aglomeração produtiva. No local, estão concentradas firmas de diversos segmentos do setor, entre elas, algumas de destaque internacional na fabricação de motores elétricos, compressores e fundição. Stallivieri (2004) destaca, no entanto, que firmas de diversos portes gastam em atividades de P\&D. Entre as microempresas, em média, 4,7\% do faturamento é destinado às atividades internas de $\mathrm{P} \& \mathrm{D}$; nas pequenas e médias, as porcentagens chegam a $6,2 \%$ e $7,3 \%$, respectivamente, ao passo que as grandes investem, em média, $2,55 \%$ de seu faturamento na atividade.

Com exceção da cooperação entre clientes e fornecedores, a cooperação com os demais agentes é baixa. No que se refere ao uso das fontes de informação, segue a tendência setorial que destaca o uso das informações oriundas dos clientes e dos consumidores, uma vez que se trata de um setor marcado pela presença de diversos segmentos "fornecedores especializados" (Pavitt, 1984). E em Joinville a importância dos clientes e dos fornecedores combina com o uso das fontes internas às firmas, revelando a existência de rotinas para inova- ção capazes de dar sustentação à capacitação tecnológica das firmas.

Também o aglomerado têxtil-vestuarista de Blumenau apresenta indicadores que se destacam. Ao lado, grande número de empresas que despenderam recursos com a aquisição de máquinas e equipamentos (207) empresas, 42 realizaram gastos com $\mathrm{P} \& \mathrm{D}$ interno à empresa.

No aglomerado têxtil-vestuarista e no plástico-químico de Joinville, o que indica seu dinamismo tecnológico são os gastos médios com $\mathrm{P} \& \mathrm{D}$ interno, com aquisições de P\&D e conhecimentos externos, que se situam entre os maiores do Estado.

O Quadro 2 procura resumir as semelhanças e as diferenças das características dos processos de aprendizagem analisadas acima.

\section{6_Conclusões}

Nesta análise exploratória, viu-se que, ainda que as taxas de inovação nas aglomerações industriais catarinenses sejam, em geral, maiores do que a taxa nacional, a incorporação de tecnologia por meio da aquisição de máquinas e equipamentos segue sendo a principal prática de inovação, a exemplo do que ocorre geralmente entre as firmas brasileiras. 
Quadro 2_ Principais características tecnológicas dos agrupamentos formados das empresas inovadoras dos locais/setores analisados de Santa Catarina de 2001 a 2003

Características dos processos de aprendizagem das firmas inovadoras nas aglomerações produtivas catarinenses

\begin{tabular}{|c|c|c|c|}
\hline $\begin{array}{l}\text { Classificação/ } \\
\text { características }\end{array}$ & $\begin{array}{l}\text { Baixo dinamismo } \\
\text { tecnológico } \\
\text { (cluster 1) }\end{array}$ & $\begin{array}{l}\text { Médio dinamismo } \\
\text { tecnológico } \\
\text { (cluster 2) }\end{array}$ & $\begin{array}{l}\text { Alto dinamismo } \\
\text { tecnológico } \\
\text { (cluster 3) }\end{array}$ \\
\hline Regiões/setores & $\begin{array}{l}\text { (A) São Bento do Sul/móveis } \\
\text { (B) Criciúma/metalúrgico } \\
\text { (C) Joaçaba/madeira } \\
\text { (D) Criciúma/confecções }\end{array}$ & (A) Blumenau/eletro-metal-mecânico & $\begin{array}{l}\text { (A) Joinville/plástico/químico } \\
\text { (B) Joinville/eletro-metal-mecânico } \\
\text { (C) Joinville/têxtil/vestuarista } \\
\text { (D) Blumenau/têxtil/vestuarista }\end{array}$ \\
\hline Estrutura produtiva & $\begin{array}{l}\text { (A) } 199 \text { empresas } \\
\text { (B) } 122 \text { empresas } \\
\text { (C) } 124 \text { empresas } \\
\text { (D) } 331 \text { empresas }\end{array}$ & (A) 321 empresas & $\begin{array}{l}\text { (A) } 103 \text { empresas } \\
\text { (B) } 331 \text { empresas } \\
\text { (C) } 235 \text { empresas } \\
\text { (D) } 1.059 \text { empresas }\end{array}$ \\
\hline $\begin{array}{l}\text { Número de empresas } \\
\text { inovadoras }\end{array}$ & $\begin{array}{l}\text { (A) } 70 \text { empresas } \\
\text { (B) } 71 \text { empresas } \\
\text { (C) } 11 \text { empresas } \\
\text { (D) } 75 \text { empresas }\end{array}$ & (A) 114 empresas & $\begin{array}{l}\text { (A) } 23 \text { empresas } \\
\text { (B) } 157 \text { empresas } \\
\text { (C) } 141 \text { empresas } \\
\text { (D) } 370 \text { empresas }\end{array}$ \\
\hline $\begin{array}{l}\text { Direcionamento dos } \\
\text { gastos inovativos }\end{array}$ & $\begin{array}{l}\text { Principalmente na aquisição } \\
\text { de M\&E }\end{array}$ & $\begin{array}{l}\text { Principalmente na aquisição de } M \& E \text {, } \\
\text { mas também em atividades de P\&D }\end{array}$ & $\begin{array}{l}\text { Na aquisição de } \mathrm{M} \& E \text {, em } P \& D \\
\text { interno e externo, na aquisição de } \\
\text { outros conhecimentos externos e em } \\
\text { projetos e preparações técnicas }\end{array}$ \\
\hline $\begin{array}{l}\text { Principais fontes } \\
\text { de informação à inovação }\end{array}$ & $\begin{array}{l}\text { Clientes, fornecedores } \\
\text { e concorrentes }\end{array}$ & Clientes e concorrentes & $\begin{array}{l}\text { Fornecedores, clientes, P\&D } \\
\text { internos, concorrentes e fontes } \\
\text { de C\&T }\end{array}$ \\
\hline
\end{tabular}

Fonte: Elaboração própria com base nos dados da Pintec/IBGE/2005. 
Nesse sentido, o uso das fontes de informação também se assemelha às práticas nacionais, uma vez que privilegiam interações com agentes de mercado, sobretudo, fornecedores e clientes. Também as práticas cooperativas se restringem a interações fornecedores e clientes, sendo, contudo, muito mais raras. A verificada freqüência de interações verticais reforça a noção da importância da interação produtor usuário aos processos de aprendizagem, apontada por Lundvall (1988).

Além dessas características gerais, importantes distinções puderam ser verificadas com base na técnica de cluster da análise estatística multivariada. Ao agregar num mesmo cluster as firmas inovadoras de diferentes setores produtivos inseridas em aglomerações localizadas numa mesma microrregião, destaca-se a influência do local nos processos de aprendizagem.

Nesse sentido, o cluster de maior dinamismo tecnológico, que agrupou firmas inovadoras de aglomerações produtivas de Joinville e Blumenau (região Norte/Nordeste do Estado), aponta um espaço indutor de um círculo virtuoso de aprendizagem tecnológica pela densidade e diversificação das estruturas industriais, bem como das estruturas institucionais de conhecimento e coordenação.

Já na região Sul do Estado, e mais especificamente em Criciúma, percebe-se um espaço emergente de diversificação industrial, caracterizado por um ambiente institucional ainda incapaz de estimular processos de aprendizagem virtuosos. As atividades industriais marcadas pelo baixo grau de conhecimentos técnicos necessários à produção e à inovação também esclarecem o restrito dinamismo tecnológico das firmas locais. Enquanto as restrições nos processos de aprendizagem nas estruturas produtivas aglomeradas em São Bento do Sul e em Joaçaba se explicam pela especialização produtiva em setores de baixo conteúdo tecnológico inseridos em estruturas industriais pouco diversificadas.

As prioridades de políticas para o estímulo a processos virtuosos de aprendizagem devem, portanto, considerar as distinções regionais e locais apontadas.

No caso das atividades localizadas em Joinville e Blumenau, as ações devem priorizar estímulos a ações cooperativas para aprendizado por meio de parcerias tecnológicas como joint ventures, por exemplo, mas também com grupos de pesquisa de engenharia da UFSC e da UFPR a fim de absorver, utilizar e difundir o conhecimento científico disponível. A ação de implementar um campus da UFSC no município de Joinville é parte desse esforço que deve ser complementado pelo incentivo a interações efetivas. 
No que tange às atividades industriais localizadas em Criciúma, a prioridade deve ser o estímulo à ampliação da diversificação e densidade industrial, especialmente através da incorporação de elos das cadeias de produção com maior intensidade tecnológica. Estímulos tributários à aquisição de componentes metal-mecânicos, têxtil e químico produzidos no local são exemplos de ações nesse sentido.

Já em Joaçaba e São Bento do Sul, a prioridade de adensamento das cadeias de produção deve ser complementada pela diversificação industrial regional, que, além de estimular processos interativos, diminui a dependência da economia regional de atividades elementares do ponto de vista da base técnica de conhecimentos.

No que se refere aos dados da Pintec e ao foco do trabalho em aglomerações produtivas, destaca-se que, ainda que as informações da Pintec tenham permitido avaliações sobre os processos de aprendizagem e capacitação nos locais, somente estudos das atividades específicas de coordenação, típicas de arranjos e sistemas produtivos e inovativos locais (Aspils), tornariam possível a caracterização dos Aspils e a conseqüente indicação de gargalos específicos a serem sanados pelas políticas públicas. 


\section{Referências bibliográficas}

BATSCHAUER, Jeanine. Arranjo produtivo eletrometal-mecânico da microrregião de Joinville/SC: um estudo da dinâmica institucional. 2004. 178 f. Dissertação (Mestrado em Economia Industrial) - Centro Sócio-Econômico, Universidade Federal de Santa Catarina, Florianópolis, 2004.

BITTENCOURT, Pablo Felipe. Dinâmica da inovação e arranjos produtivos locais: uma análise da distribuição da atividade industrial em Santa Catarina. 2006. 201 f.

Dissertação (Mestrado em Economia Industrial) - Centro Sócio-Econômico, Universidade Federal de Santa Catarina, Florianópolis, 2006.

BRASIL. Ministério do Trabalho e Emprego. Departamento de Emprego e Salários. Bases Estatísticas. Relação Anual de Informações Sociais (Rais). Brasília, 2003. (RAIS/MTE. RAIS - Relação Anual de informações sociais. MTE - Ministério do Trabalho e Emprego. Departamento de Emprego e Salários. Bases estatísticas. Brasília, 2003)
BRESCHI, B.; MALERBA, F. Sectorial system of innovation: technological regimes, schumpeterian dynamics and spatial bounderies. In: EDQUIST, C. System of innovation, technologies, institutions and organizations. London and Washinton Pinter, p. 130-155, 1997.

BRITO, J. N.; STALIVIERI, F.; CAMPOS, R. R.; VARGAS, M.

Padrões de aprendizagem, inovação e cooperação em aglomerações produtivas do Brasil: uma análise multivariada exploratória. In: ENCONTRO NACIONAL DE ECONOMIA, 35., 2007, Recife. [Anais

Eletrônicos...] Recife: Anpec, 2007. 1 CD-ROM.

CAMPOS, R. R.; BITTENCOURT, P. F. Bases produtivas locais para estímulo de APLs em Santa Catarina: In: ENCONTRO DE ECONOMIA DA REGIÃO SUL, 9., 2006, Florianópolis. Anais... Florianópolis, 2006.
CAMPOS, R. R.; CÁRIO, S. A. F.; NICOLAU, J. A; LINS, H. N.; BARBOSA, C. R. F.

Reestruturação industrial e aglomerações setoriais locais em Santa Catarina. In: VIEIRA, P. F. (Org.). A pequena produção e o modelo catarinense de desenvolvimento. Florianópolis: APED, 2002.

CAMPOS, Renato R.; CÁRIO, Sílvio A. F.; NICOLAU, José A. Arranjo produtivo têxtil-vestuário do Vale do Itajaí/SC (Relatório de Pesquisa). Florianópolis: UFSC, 2000. (BNDES/Finep/FUJB).

CÁRIO, S. F. A. et al. Arranjos produtivos de transformados plásticos das regiões Nordeste e Sul. In: CÁRIO, S. F. A.

FAUSTINO, E.;

MONTIBELLER, G. Programa estratégico de desenvolvimento com base na inovação para o Estado de Santa Catarina. Rio de Janeiro: 2005.

CASSIOLATO, J. E.; LASTRES, M. H. M. Sistemas de inovação e desenvolvimento: as implicações de política. São Paulo em Perspectiva, São Paulo, v. 19, n. 1, p. 34-45, jan./mar. 2005.
CASSIOLATO, J. E.; LASTRES M. H. M. O foco em arranjos produtivos e inovativos locais de micro e pequenas empresas. In: CASSIOLATO, J. E.; LASTRES, M. H. M.; MACIEL, M. L.

Pequena empresa cooperação e desenvolvimento local. Rio de Janeiro: Relume Dumará/IE-Uferj, 2003.

CASSIOLATO, J. E.; CAMPOS R. R.; STALLIVIERI, F. Processos de aprendizagem e inovação em setores tradicionais: os arranjos produtivos locais de confecções no Brasil. In: ENCONTRO NACIONAL DE ECONOMIA, 34., 2006, Salvador. [Anais Eletrônicos...] Salvador: Anpec, 2006.

COUTINHO, L.; FERRAZ, J. C. (Coord.). Estudo da competitividade da indústria brasileira. 3. ed. Campinas: Papirus, 1995. 510p.

DENK, A. Dinâmica competitiva do cluster moveleiro da região de São Bento do Sul-SC. $2002.250 \mathrm{f}$.

Dissertação (Mestrado em

Economia Industrial) Universidade Federal de Santa Catarina, Florianópolis, 2002. 
EDQUIST, C. The system of innovation approach and innovation policy: an account of the state of the art. DRUID Conference, Aalborg, June 2001.

ENDERLE, R.; CÁRIO, S.; NICOLAU, J. A. Estudo do arranjo produtivo local madeireiro do Vale do Iguaçu (PR/SC): capacitação tecnológica e política de desenvolvimento. Revista Paranaense de Desenvolvimento, Curitiba, n. 108, p. 113-141, jan./jun. 2005.

FORAY, D.; LUNDVALL, B. A The knowledge based economy: from the economics of knowledge to the learning economy. Employment and growth in the knowledge-based economy. OCDE Documents, 1999.

FREEMAN, C. Technology and economic performance: lessons from Japan. London: Printer, 1987.

GEREMIA, F. Dinâmica competitiva e processos de aprendizagem do arranjo produtivo moveleiro da região Oeste de Santa Catarina. 2004. 164 f.

Dissertação (Mestrado em

Economia Industrial) - Centro

Sócio-Econômico, Universidade

Federal de Santa Catarina,

Florianópolis, 2004

INSTITUTO BRASILEIRO DE GEOGRAFIA E ESTATÍSTICA

- IBGE. Pesquisa Brasileira de

Inovação Tecnológica II.

(PINTEC/IBGE. Pesquisa

Industrial de Inovação e

Tecnologia do Instituto Brasileiro de Geografia e Estatística). Rio de Janeiro: IBGE, 2005.
JOHNSON, R. A.; WICHEWRN, D. W. Applied multivariate statistical analysis. 4 (ed) Upper Saddle River: Prentice-Hall, 1998.

LUNDVALL, B. A. Innovation as an interactive process: from user-producer interaction to the national system of innovation. In: DOSI, G. et al. Technical change and economic theory. London: Pinter Publishers, 1988.

LUNDVALL, B. A. National systems of innovation: towards a theory of innovation and interactive learning. London: Pinter Publishers, 1992.

MANLY BRYAN, F. J.

Multivariate statistical methods: a primer. 3rd. ed. Chapman \& Hall, 1944.

PAVITT, K. Sectoral patterns of technical change: towards a taxonomy and a theory. Research Policy, n. 13, v. 6, p. 343-373, 1984.

QUADROS, R. C. (Coord.). Indicadores de ciência, tecnologia e inovação em São Paulo. São Paulo: Fapesp, 2005.

STALLIVIERI, F. Dinâmica econômica e a insercão de micro e pequenas empresas em arranjos produtivos locais: o caso da eletro-metal-mecânica na microrregião de Joinville/SC. 2004. 212 f. Dissertação Mestrado em Economia Industrial) - Universidade Federal de Santa Catarina, Florianópolis, 2004
STALLIVIERI, F.; CAMPOS, R. R.; BRITO, J. N. P. Capacitações tecnológicas de micro e pequenas empresas inseridas em redes tecnoprodutivas: o acaso da eletro-metal-mecânica em Joinville SC. R. Econ. Contemp. Rio de Janeiro, v. 11, n. 3, p. 439-474, set./dez. 2007.

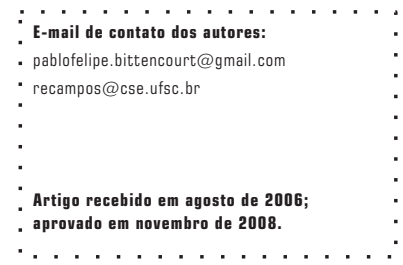

